\title{
Welcome to the New Open Access Reports
}

\author{
Toshio Hattori \\ Department of Occupational Therapy, School of Health Science and Social Welfare, KIBI International Univesrity, \\ 8 Igamachi, Takahashi, Okayama, Japan; hattorit@kiui.ac.jp; Tel.: +81-866-22-9469; Fax: +81-866-22-9469
}

Received: 27 November 2017; Accepted: 27 November 2017; Published: 28 November 2017

With sincere satisfaction and pride, I present to you the new Journal, Reports, for which I am pleased to serve as Editor-in-Chief. To date, there have been several scientific international journals present in the literature on case reports; Reports is online, peer reviewed, with a quick turnaround time from submission to publication, and without any limit regarding length of papers! Our aim is to improve the management of patients by compiling reports across all medical disciplines that are both practical and useful for clinicians, researchers, healthcare professionals, and other relevant care providers. Reports will publish novel information on the management of patients. Therefore, I am honored to introduce Reports, which has been created to serve as a hub for disseminating new findings and discoveries in clinical medicine to clinicians and medical researchers worldwide. It is unnecessary to stress the importance of case reports as all clinicians seek to observe patients scientifically. Strictly speaking, since genetic and environmental backgrounds always differ, it is worthwhile to report on all patients. Therefore, writing clinical reports is the best educational tool for clinical management. It is also important to describe detailed clinical symptoms as they are, but equally important to take a step forward and search for innovative solutions. Thanks to recent efforts, new scientific fields such as human retro virology (adult $\mathrm{T}$ cell leukemia, acquired immune deficiency syndrome), have emerged from the reports of unique clinical findings of the patients.

In our current global society, there are widely used medical technologies in each society to treat patients with various values. Additionally, since each patient's living environment differs, clinical symptoms are also expected to differ. These differences may also be the source of new insights. We therefore encourage authors to describe the cultural and environmental background of patients in Reports. The management and therapy of the individual patient should be described along with the international standard therapy. From these points of view, I believe that new knowledge related to patient management will be generated in Reports.

Our aim is to develop a journal that will constitute a valuable tool for both learning and research, and will develop as an important scientific hub for clinical management. Reports could represent an interesting forum for all researchers involved in clinical medicine.

We invite you to submit your case reports and articles, and join us in making this new journal a success.

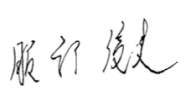

(C) 2017 by the author. Licensee MDPI, Basel, Switzerland. This article is an open access article distributed under the terms and conditions of the Creative Commons Attribution (CC BY) license (http://creativecommons.org/licenses/by/4.0/). 